\title{
Modifications of nutrient regime, chlorophyll-a, (rosesart and trophic state relations in Daechung Reservoir after the construction of an upper dam
}

\author{
Neha P. Ingole and Kwang-Guk $A n^{*}$
}

\begin{abstract}
Background: Previous numerous studies on watershed scale demonstrated that the constructions of upper dams may influence the below dams due to modifications of flow regime and nutrient inputs. Little is known about how the dam constructions influence the downstream lakes or reservoirs in the regional scale. This study demonstrates how the construction of upper dam (i.e., Yongdam Dam) influences nutrient regime, trophic relations, and empirical models in Daechung Reservoir (DR). Yongdam Dam was constructed at the upstream region of DR in year 2000.

Results: The analysis of hydrological variables showed that inflow and discharge in the DR were largely reduced after the year 2000. The construction of upper dam construction also resulted in increases of water temperature, $\mathrm{pH}$ and conductivity (as an indicator of ionic content) in the DR. Empirical models of TP-CHL and N:P ratio-CHL suggested that stronger responses of $\mathrm{CHL}$ to the phosphorus were evident after the upper dam construction, indicating that algal production at a unit phosphorus increased after the upper dam construction. Mann-Kendall tests on the relations of $\mathrm{N}: \mathrm{P}$ ratios to TN showed weak or no relations ( $t_{\mathrm{au}}=-0.143, z=-0.371, p=0.7105$ ) before the dam construction, while the relation of N:P ratios to TP showed strong in the periods of before- $\left(t_{a u}=-0714, z\right.$ $=-2.351, p=0.0187)$ and after the construction ( $t_{\mathrm{au}}=-0.868, z=-4.270, p=0.0000$ ). This outcome indicates that TP is key determinant on N:P ratios in the reservoir. Scatter Plots on Trophic State Index Deviations (TSIDs) of "TSI(SD) - TSI(CHL)" against "TSI(TP) - TSI(CHL)" showed that the dominance of clay turbidity or light limitation was evident before the upper dam construction $[T S I(T P)-T S I(C H L)>0$ and TSI(SD) - TSI(CHL) $>0$ ] and phosphorus limitation became stronger after the dam construction [(TSI(TP) - TSI(CHL) $<0$ and TSI(SD) - TSI(CHL) $>0]$.
\end{abstract}

Conclusions: Overall, our analysis suggests that the upper dam construction modified the response of trophic components (phytoplankton) to the nutrients or nutrient ratios through the alteration of flow regime, resulting in modifications of ecological functions and trophic relations in the low trophic levels.

Keywords: Upper dam construction, Trophic state deviation, Nutrient regime, Seasonality

\section{Background}

The Daechung Reservoir is located on the upper part of the Geum River in the central region of South Korea and has a surface area of $6.8 \times 107 \mathrm{~m}^{2}$, a volume of $14.3 \times 108 \mathrm{~m}^{3}$, a mean depth of $21.2 \mathrm{~m}$, and a maximum depth of $69 \mathrm{~m}$ at an elevation of $80 \mathrm{~m}$ above mean sea level (MSL). This reservoir was formed by the construction of a multipurpose dam in 1980 to conserve water resources for drinking, agricultural, and industrial use and for electric power supply. This reservoir supplies water to several central regions including Daejeon,

* Correspondence: kgan@cnu.ac.kr

Department of Biological Sciences, College of Biological Sciences and

Biotechnology, Chungnam National University, Daejeon 34134, South Korea
Chongju, and Chonahn cities. This reservoir is a large branch-type lake with a 72-m-high dam and a gross storage capacity of $1490 \mathrm{Mm}^{3}$ (Oh et al. 2001). Previous studies of reservoirs (artificial lakes; Kimmel and Groeger 1984; Kennedy et al. 1985; Cole and Hannan 1990) pointed out that spatial heterogeneities in physical structure, chemical water quality, and biological components are large and temporal variations are large due to large fluctuations of rainfall and/ or runoff from the watershed. Such heterogeneity is mainly attributed to greater flushing rate than natural lakes (Canfield and Bachmann 1981; Straskraba 1996).

Reservoir ecosystems typically have prominent longitudinal heterogeneities in water quality from the 
headwaters to the dam (Kennedy et al. 1982, 1985; Kimmel et al. 1990). Spatial and temporal variabilities of nutrients, trophic state, and algal productions are large in reservoir ecosystems, and the variabilities are especially greater in monsoon regions (Asia) than non-monsoon regions (Park et al. 2010). Typical longitudinal gradients in the Daechung Reservoir were evident in nutrients $(\mathrm{N}, \mathrm{P})$, water transparency, suspended solids, and algal biomass (An and Park 2002; An and Jones 2000); thus, the functional zones were divided into three reaches along the main axis of the reservoir from the headwaters to the dam (An and Park 2002; Sedell et al. 1990). The riverine zone (running water) which is mainly influenced by external inputs and is frequently light limited showed high total phosphorus (TP), high inorganic turbidity, and low Secchi depth (Oberholster et al. 2013; Irigoien and Castel 1997; O’Boyle et al. 2015), and the length was maximized in the flooding monsoon (Puckridge et al. 2000).

Although phosphorus is a primary limiting nutrient for algal growth in temperate regions (Correll 1999), light limitation is frequently found in the riverine zone during the flooding season (Lehman et al. 2007). Under these circumstances, nitrogen or phosphorus may not be a key factor regulating the primary production in the reservoir (Sterner 2008) In contrast, the lacustrine zone (stagnant water) which is lake-like and influenced by internal processes showed low nutrients $(\mathrm{N}, \mathrm{P})$, high availability of underwater light (Havens et al. 2003), and low primary productivity as chlorophyll-a. The transition zone is between the riverine and lacustrine zones, and the characteristics were intermediate, compared to the riverine and lacustrine zones. Also, the Daechung Reservoir has high temporal variations of limnological parameters seasonally due to intense Asian monsoon rain during the short period of July-August. Thus, longitudinal characteristics of the three zones were largely modified by the monsoon flow. Ionic contents in the lake water were diluted by the rainwater and most pronounced in the riverine zone by high flow (Moss 1998). An and Park (2002) found that the relations in empirical models of chlorophyll-a (CHL)TP were largely modified depending on the location of the functional zones, and the light limitation is most pronounced in the riverine zone during the monsoon.

Under the high spatial and temporal variabilities of limnological conditions in the Daechung Reservoir (DR), the Yongdam Dam (YD) was constructed at the upstream region of the DR in 2000. Thus, flow regime and hydrology in the DR were probably modified due to the constructions of the YD. Serial discontinuity concepts (SDCs; Ward and Stanford 1983) hypothesized that river nutrient cycling is strongly altered by constructions of the upper dam, especially in low to mid-region waterbodies, even though empirical evidence of such a pattern is not strong. This hypothesis implies that the construction of the YD may alter the nutrient regimes and trophic state in the DR, resulting in modifications of algal response to nutrients $(\mathrm{N}, \mathrm{P})$.

Currently, little is known about research outcomes on how the constructions of the upper dam influence the downstream waterbody of the DR. Such construction

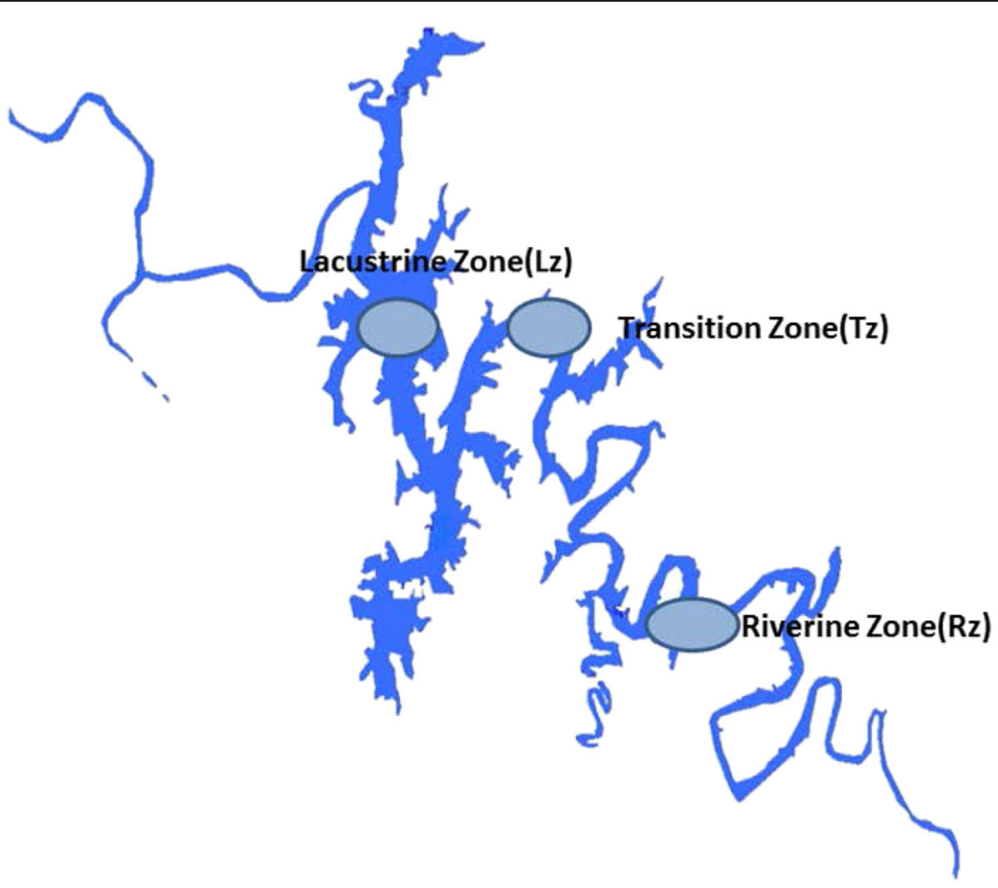

Fig. 1 Map of the Daechung Reservoir showing the three sampling sites of riverine $(R z)$, transition $(T z)$, and lacustrine zones $(L z)$ 
may reduce inflows and outflows to DR, and these hydrological factors, in turn, may directly influence the $\mathrm{N}: \mathrm{P}$ ratios and yields of chlorophyll per unit of nutrients $(\mathrm{N}$ or $\mathrm{P})$, resulting in modifications of the eutrophication processes in DR. The objective of the present study was to evaluate the influence of the YD on nutrient regime, algal response, light availability in the DR with an emphasis on how flow regime influenced spatially (riverine, transition, and lacustrine zone) the water chemistry along the length of this morphologically complex reservoir and how the conditions vary seasonally (premonsoon, monsoon, and postmonsoon) in relation to the Asian monsoon. For the analysis, empirical relations of CHL-nutrients and Trophic State Index Deviations (TSIDs) were demonstrated in this study.

\section{Methods}

\section{Site description and data collection}

The DR is located in the middle of Geum River, Chungbuk and Chungnam Provinces, Korea ( $36^{\circ} 50 \mathrm{~N}, 127^{\circ} 50 \mathrm{E}$ ) and was formed in December 1980 by construction of a dam (Fig. 1). The reservoir is identified as a dendritic-type waterbody with longitudinal gradients from the headwaters to the dam. The reservoir has two intake towers of Muneu and Dongmeon areas for drinking water supplies and has a surface area of $6.8 \times 10^{7} \mathrm{~m}^{2}$, a volume of $14.3 \times 10^{8} \mathrm{~m}^{3}$, a mean depth of $21.2 \mathrm{~m}$, and a maximum depth of $69 \mathrm{~m}$.

In this reservoir, three sampling sites were designated in order to cover the longitudinal gradients of the reservoir depth. The longitudinal zones in the reservoir were divided into three categories of riverine $(\mathrm{Rz})$, transition (Tz), and lacustrine zones (Lz; Fig. 1). The Rz reflects the headwater zone, and the $\mathrm{Lz}$ reflects the down lake near the dam region. The $\mathrm{Tz}$ reflects the intermediate characteristics between the $\mathrm{Rz}$ and Lz. Seasonal variations were also considered in the analysis; the terms of premonsoon (January-June), monsoon (July-August), and postmonsoon (September-December) were used in describing the temporal conditions.

\section{Chemical variables and trophic state analysis}

The seasonal and spatial variations were total nitrogen (TN) and TP in DR along with total suspended solids (TSS) and CHL. Long-term limnological data from 1992 to 2013 were analyzed, and this was obtained from the Water Information System, Ministry of Environment,

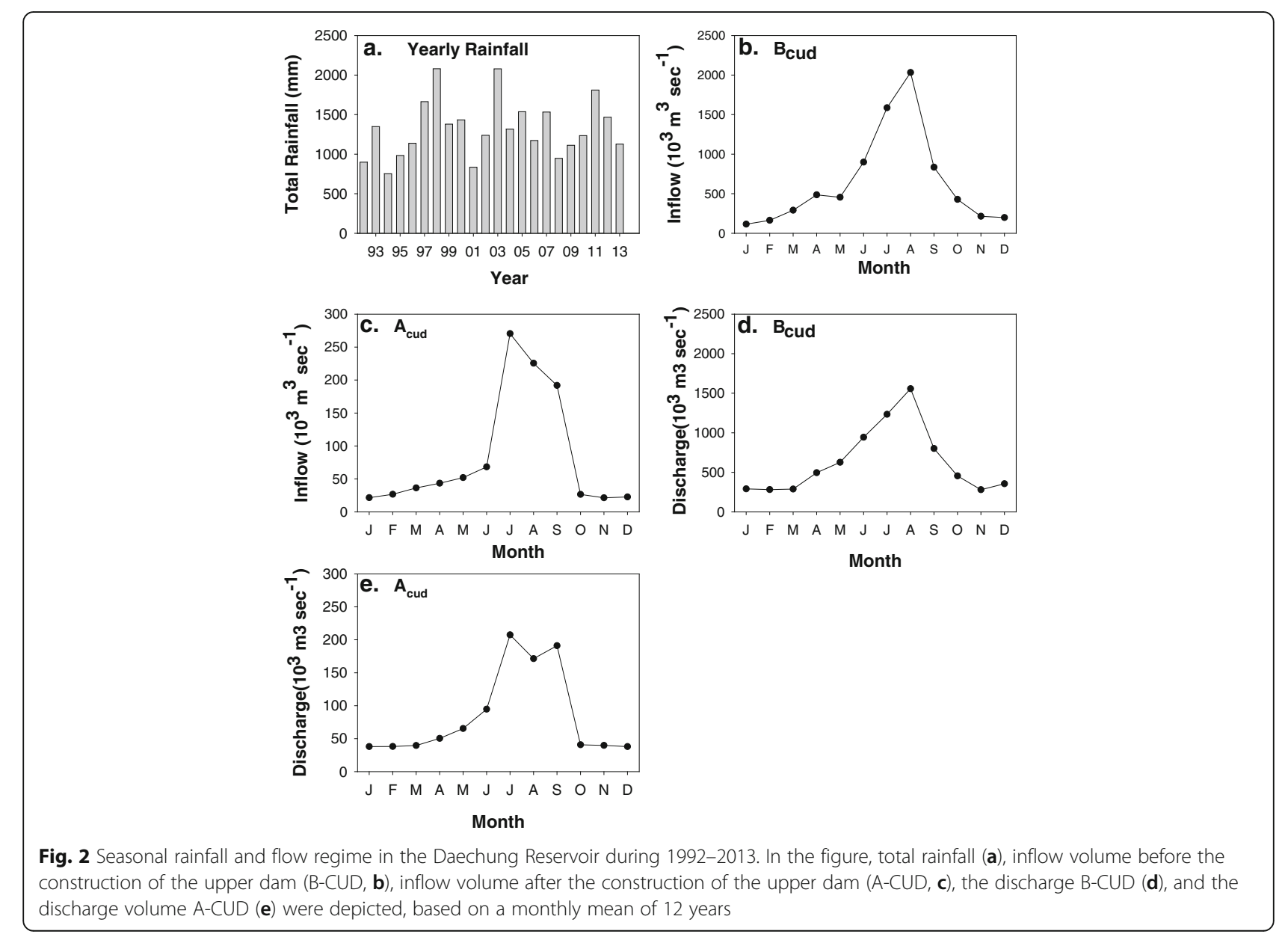


South Korea. TP was determined using the ascorbic acid method after persulfate oxidation (Prepas and Rigler 1982), and TSS were filtered by GF/C filters. CHL concentration was measured by using a spectrophotometer after extraction in hot ethanol (Sartory and Grobbelaar 1984). Secchi transparency (i.e., Secchi depth) was estimated from the empirical equation of TSS. Annual, monthly, and seasonal mean data were log-transformed in order to follow the regression analysis requirements. Statistical analyses were performed using a Sigma Plot (Systat Software Inc.). The calculations of Trophic State Index (TSI) were followed by the approach of Carlson (1977), and the values of trophic parameters were calculated in the three zones and seasons using the three equations as follows:

$$
\begin{aligned}
& \mathrm{TSI}(\mathrm{TP})=14.42 \operatorname{Ln}(\mathrm{TP})+4.15 \\
& \mathrm{TSI}(\mathrm{TN})=14.43 \operatorname{Ln}(\mathrm{TN})+54.45 \\
& \mathrm{TSI}(\mathrm{SD})=-14.41 \operatorname{Ln}(\mathrm{SD})+60 \\
& \mathrm{TSI}(\mathrm{Chl})=9.81 \operatorname{Ln}(\mathrm{Chl})+30.6
\end{aligned}
$$

The criteria of TSI were followed by the approach of Carlson (1977); values of TSI less than 40 were grouped into oligotrophic state, and the values of $40-50$ and 50-70 were categorized as mesotrophic and eutrophic states, respectively. Values higher than 70 are considered as hypertrophic state (Carlson 1977). Non-algal light attenuation coefficient $\left(K_{\mathrm{na}}\right)$ was estimated in order to evaluate the mechanisms controlling light attenuation in the water column. Non-algal light attenuation was calculated using the following formula:

$$
K_{\text {na }}=1 / \mathrm{SD}-0.025 \mathrm{Chl}
$$

\section{Statistical analysis}

Annual and seasonal mean data of trophic variables such as TN, TP, Secchi depth (SD), and CHL were logtransformed to normalize for the requirements of parametric regression analysis. In addition, we identified the annual trend and the trend analysis over the long-term period was performed by an approach of Mann-Kendall statistical test.

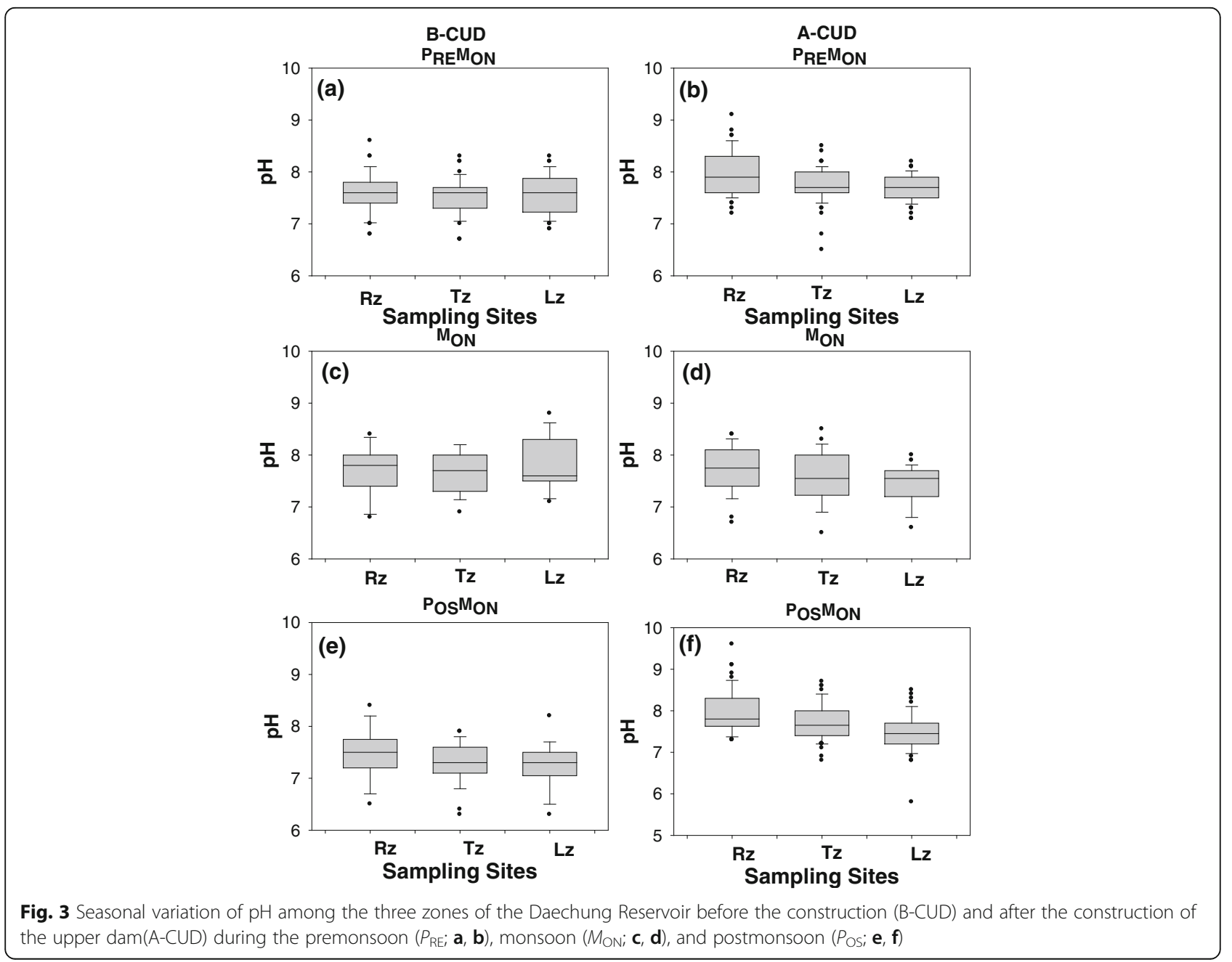




\section{Results and discussion}

Modifications of flow regime after the upper dam construction

Annual and seasonal flow regime in DR is directly determined by rainfall patterns. During the study period of 1992-2013, high rainfalls occurred in the years of 1998, 2003, and 2011 and the maximum of $1738 \mathrm{~mm}$ was found in 1998 (Fig. 2). These periods were evidently flood years. In contrast, low rainfalls occurred in the years of 1994, 2001, and 2008 (Fig. 2a) and the minimum of $638 \mathrm{~mm}$ was found in 1994, indicating that these periods were drought years. In the meantime, rainfalls in the remaining years had no big differences (Fig. 2a).

Monthly inflow and discharge volume showed large differences between the two periods before (B-CUD) and after the construction of the upper dam (A-CUD). The largest differences of inflow and discharge volume between the B-CUD and A-CUD occurred in the monsoon season of July-August; monthly inflow was $2032.38 \mathrm{~m}^{3}$ B-CUD in the August vs. $225.51 \mathrm{~m}^{3}$ A-CUD in the August, while monthly dischange was $1575.42 \mathrm{~m}^{3}$ B-
CUD in the August vs. $171.39 \mathrm{~m}^{3}$ A-CUD in the August. In other words, inflow volume in the B-CUD directly influenced by rainfall, but the response was really weak in the A-CUD. Our observation of inflow and discharge volume suggests that large inflow and outflow volumes were reduced after the upper dam construction, especially during the monsoon of July-August. These hydrological changes after the upper dam construction may modify the nutrient regime, solid dynamics, ionic contents, and algal growth in DR.

\section{Spatio-temporal variation of $\mathrm{pH}$, water temperature, and conductivity}

The construction of the YD resulted in increases of $\mathrm{pH}$ in DR. Before the dam construction (B-CUD), the mean values of $\mathrm{pH}$ during the premonsoon were $<7.5$ in the all three zones of $\mathrm{Rz}, \mathrm{Tz}$, and Lz (Fig. 3a). But, after the dam construction (A-CUD), the $\mathrm{pH}$ values during the premonsoon were $>7.5$ in all the three zones (Fig. 3b). These results suggest that during the premonsoon, the mean $\mathrm{pH}$ was significantly greater after the upper dam
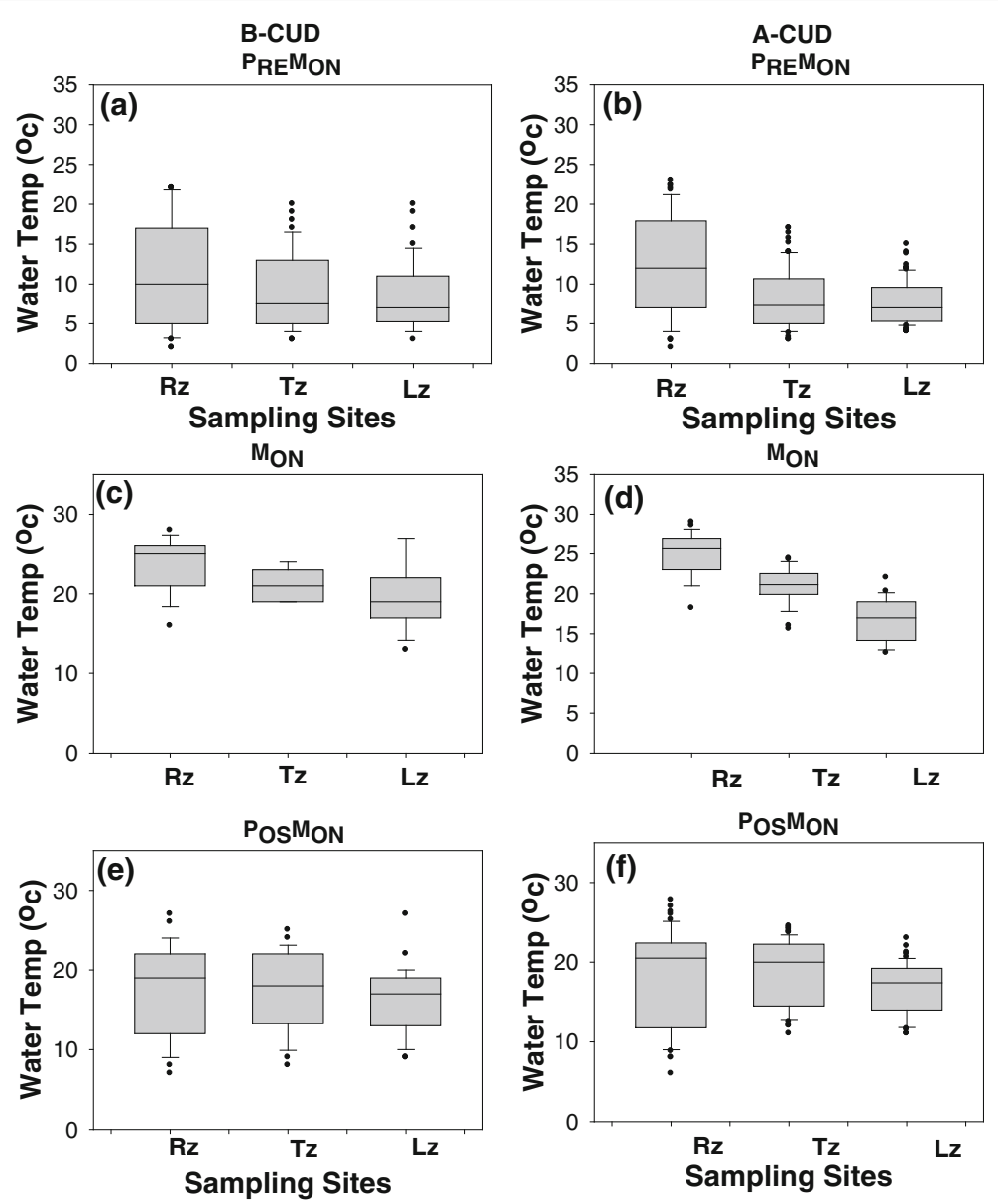

Fig. 4 Seasonal variation of water temperature among the three zones of the Daechung Reservoir before and after the construction of the upper dam during premonsoon $(\mathbf{a}, \mathbf{b})$, monsoon $(\mathbf{c}, \mathbf{d})$, and postmonsoon $(\mathbf{e}, \mathbf{f})$ 
construction. During the monsoon, $\mathrm{pH}$ values, however, did not show a significant difference between the BCUD and A-CUD (Fig. 3c, d). The differences in the mean $\mathrm{pH}$ between the B-CUD and A-CUD were most pronounced during the postmonsoon (Fig. 3e, f). We believe that $\mathrm{pH}$ increased after the upper dam construction.

The construction of the upper dam also resulted in increases of water temperature $\left(W_{t}\right)$ in the DR, and this was similar to the $\mathrm{pH}$. During the premonsoon, the mean $W_{\mathrm{t}}$ in the $\mathrm{Rz}$ was significantly greater in the ACUD $\left(9.8{ }^{\circ} \mathrm{C}\right)$ than the B-CUD $\left(11.3^{\circ} \mathrm{C}\right)$ while the mean $W_{\mathrm{t}}$ in the $\mathrm{Tz}$ and $\mathrm{Lz}$ was similar between the A-CUD and B-CUD (Fig. 4a, b). During the monsoon, the mean $W_{\mathrm{t}}$, however, did not show a significant difference between the B-CUD and A-CUD (Fig. 4c, d). In the postmonsoon, the mean $W_{\mathrm{t}}$ in the two zones of $\mathrm{Tz}$ and $\mathrm{Lz}$ were greater in the A-CUD $\left(>20{ }^{\circ} \mathrm{C}\right)$ than the B-CUD $\left(<20{ }^{\circ} \mathrm{C}\right)$. This outcome indicates more increases of mean $W_{\mathrm{t}}$ in the $\mathrm{Rz}$ than the $\mathrm{Lz}$ and agrees with previous researches (Wetzel 2001) that water temperature increased after the dam construction. Similarly, specific conductivity (at $25{ }^{\circ} \mathrm{C}$ ) in the DR increased after the upper dam (YD) construction. This trend was evident in each premonsoon, monsoon, and postmonsoon season and also same as each zone of riverine, transition, and lacustrine (Fig. 5). The largest differences of conductivity between the B-CUD and A-CUD occurred in the Rz, shown in $\mathrm{pH}$ and water temperature.

\section{Influence of the Yongdam Dam on empirical relations of trophic variables in the Daechung Reservoir}

The empirical models of TN-CHL, TP-CHL, and N:PCHL showed distinct differences between the B-CUD and A-CUD when we used all the sites (three sites at three zones plus other two sites $=$ total five sites) in the DR (Fig. 6). There was no big difference in the relation of TN-CHL of the DR between the B-CUD and A-CUD. However, the relation of log-transformed TP-CHL in the A-CUD was modified in the DR; the relation was not significant $(p>0.05)$ before the dam construction but became very positively strong after the dam construction (Fig. 6c, d). Our analysis indicates that algal production

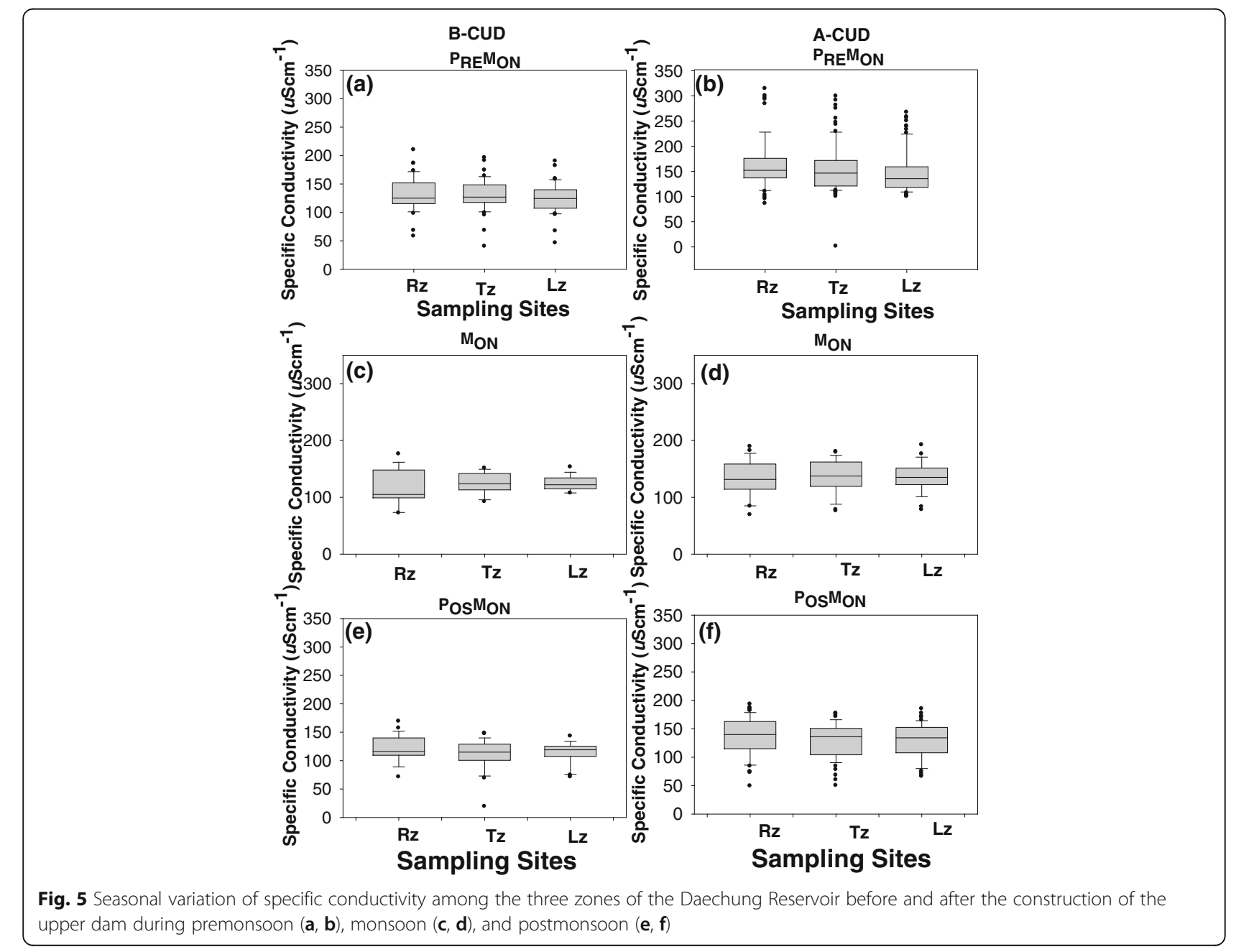



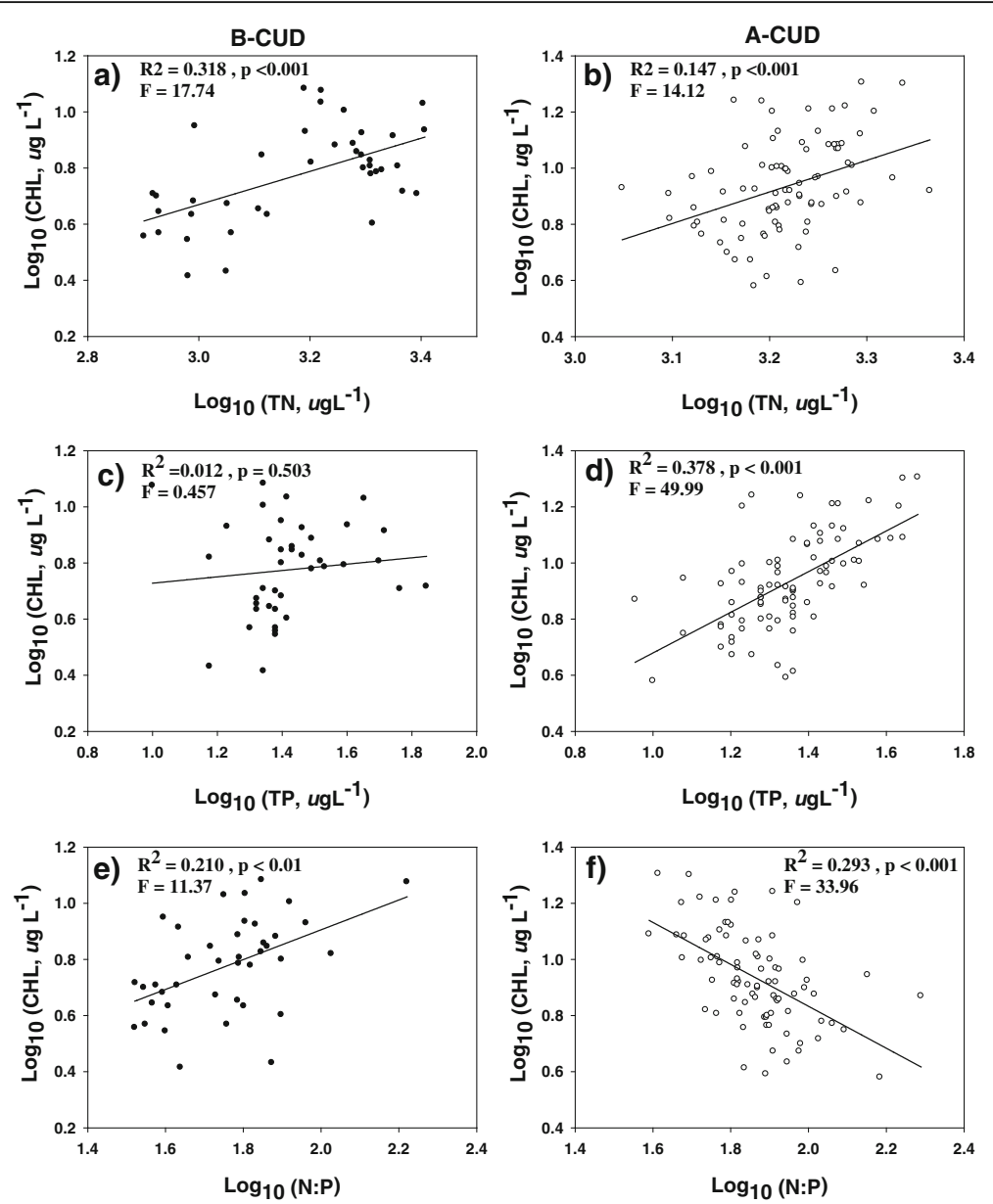

Fig. 6 The empirical models of TN-CHL, TP-CHL, and N:P-CHL in the Daechung Reservoir before the construction of the upper dam (a, $\mathbf{c}$, e) and after the construction of the upper dam $(\mathbf{b}, \mathbf{d}, \mathbf{f})$

at a unit phosphorus increased after the upper dam construction and the input of phosphorus from the watershed may increase the eutrophication more rapidly, compared to the period B-CUD. This phenomenon was also supported by the relation of log-transformed CHL$\mathrm{N}: \mathrm{P}$ (Fig. 6e, f). The relation of N:P-CHL was positive during the period A-CUD but became negative after the upper dam construction. In other words, increases of $\mathrm{N}: \mathrm{P}$ mass ratios resulted in less chlorophyll, so the CHL was directly associated with the magnitude of N:P ratios. These data suggests that the upper dam construction modified the ecological functions by the changes of trophic relations in the reservoir.

\section{Relations of $\mathrm{N}: \mathrm{P}$ ratios to nutrient regime and Mann-Kendall tests}

Regression analysis of log-transformed N:P ratios on nutrient regime showed that functional relations of $\mathrm{N}: \mathrm{P}$ were changed after the upper dam construction of the Yongdam Reservoir. We found that N:P ratios were more strongly determined by phosphorus rather than nitrogen. Especially, the N:P ratios after the upper dam construction were not determined by TN. Thus, the regression model of log-transformed TN:TP against TN indicates stronger relation in the period after the dam construction than before the construction (Fig. 7a, b). The regression slope in the relation of N:P vs TN was 5.27 and 1.12 in the periods B-CUD and A-CUD, respectively (Fig. 7), and the relation became weak $\left(R^{2}=\right.$ $0.97, p<0.001)$ after the upper dam construction. In the mean time, $\mathrm{N}: \mathrm{P}$ ratios were strongly influenced by phosphorus (Fig. 7c, d). This outcome suggests that the N:P ratios, frequently used as an index of nutrient limitation, were determined by the ambient concentrations of phosphorus.

In addition, Mann-Kendall tests on the relations of $\mathrm{N}: \mathrm{P}$ ratios to TN showed weak or no relations in the periods B-CUD $\left(t_{\mathrm{au}}=-0.143, z=-0.371, p=0.7105\right)$ and A-CUD $\left(t_{\mathrm{au}}=-0.187, z=-0.876, p=0.3811\right.$; Table 1$)$, indicating that the role of nitrogen to $\mathrm{N}: \mathrm{P}$ was minor and 

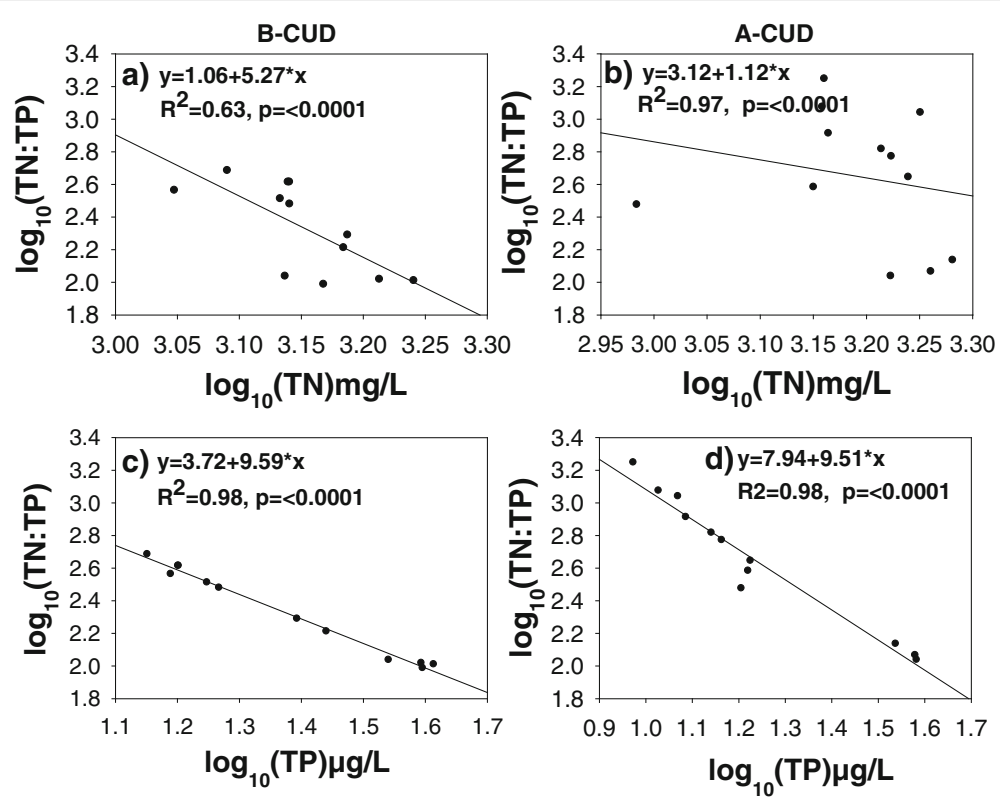

Fig. 7 The graph of regression analyses of log-transformed TN:TP against TN in the Daechung Reservoir B-CUD (a) and A-CUD (b) and regression analyses of log-transformed TN:TP against TP B-CUD (c) and A-CUD (d)

did not largely change. In the meantime, the relations of $\mathrm{N}: \mathrm{P}$ ratios to TP were strong in the periods $\mathrm{B}$ CUD $\left(t_{\mathrm{au}}=-0.714, z=-2.351, p=0.0187\right)$ and A-CUD $\left(t_{\mathrm{au}}=-0.868, z=-4.270, p=0.0000\right.$; Table 1$)$. This result indicates that TP is an important determinant on $\mathrm{N}: \mathrm{P}$ ratios, and the role did not change after the upper dam construction.

\section{Relations of Trophic Sate Index (TSI) among the variables and the analysis of TSI deviation}

A scatter plot of "TSI(SD) - TSI(CHL)" against "TSI(TP) TSI(CHL)" before the upper dam construction indicated that about $93 \%$ of the total observation fall into the section of $\mathrm{TSI}(\mathrm{TP})-\mathrm{TSI}(\mathrm{CHL})>0$ and $\mathrm{TSI}(\mathrm{SD})-\mathrm{TSI}(\mathrm{CHL})>0$ (Fig. 8a). These results suggest that the dominance of clay turbidity was evident before the upper dam construction. Thus, light limitation on algal growth dominated the environment in the period before the upper dam construction, probably due to high current velocity or high clay particles. However, after the upper dam construction, turbidity of inorganic solids decreased largely, so the frequency of phosphorus limitation increased in the reservoir [TSI (TP) $-\mathrm{TSI}(\mathrm{CHL})<0$ and TSI $(\mathrm{SD})-\mathrm{TSI}(\mathrm{CHL})>0$ ]; (Fig. 8b). Thus, phosphorus limitation on algal growth dominated the environment after the upper dam construction. The changes of the environment is supported by the linear empirical models of TP-CHL and N:P ratio-CHL relations.

\section{Conclusions}

The present study demonstrates the evident influences of the upper dam construction (YD) on the DR. Empirical relations of log-transformed TP-CHL and $\mathrm{N}: \mathrm{P}$ ratio-CHL after the upper dam construction were modified. In other words, phosphorus limitation

Table 1 Mann-Kendall statistical tests on the $\log _{10}$ TN vs. $\log _{10}$ TN:TP and $\log _{10}$ TP vs. Log 10 TN:TP between the two periods before (B-CUD) and after the construction of the upper dam (A-CUD)

\begin{tabular}{|c|c|c|c|c|c|}
\hline \multicolumn{6}{|l|}{ (a) B-CUD } \\
\hline $\begin{array}{l}\text { B-CUD year } \\
(1992-1999)\end{array}$ & $t_{\mathrm{au}}$ & s & $z$ & $p$ value & Linear model \\
\hline $\log _{10}$ TN vs. $\log _{10}$ TN:TP & -0.143 & -4 & -0.371 & 0.7105 & $\log _{10}(T N: T P)=2.52-0.119 \times \log _{10}(T N)$ \\
\hline $\log _{10}$ TP vs. $\log _{10}$ TN:TP & -0.714 & -20 & -2.351 & 0.0187 & $\log _{10}(T N: T P)=3.70-1.108 \times \log _{10}(T P)$ \\
\hline \multicolumn{6}{|l|}{ (b) A-CUD } \\
\hline $\begin{array}{l}\text { A-CUD year } \\
(2000-2013)\end{array}$ & $t_{\mathrm{au}}$ & s & $z$ & $p$ value & Linear model \\
\hline $\log _{10}$ TN vs. $\log _{10}$ TN:TP & -0.187 & -17 & -0.876 & 0.3811 & $\log _{10}(T N: T P)=5.90-1.111 \times \log _{10}(T N)$ \\
\hline $\log _{10}$ TP vs. $\log _{10}$ TN:TP & 0.868 & -79 & -4.270 & 0.0000 & $\log _{10}(T N: T P)=4.54-1.616 \times \log _{10}(T P)$ \\
\hline
\end{tabular}




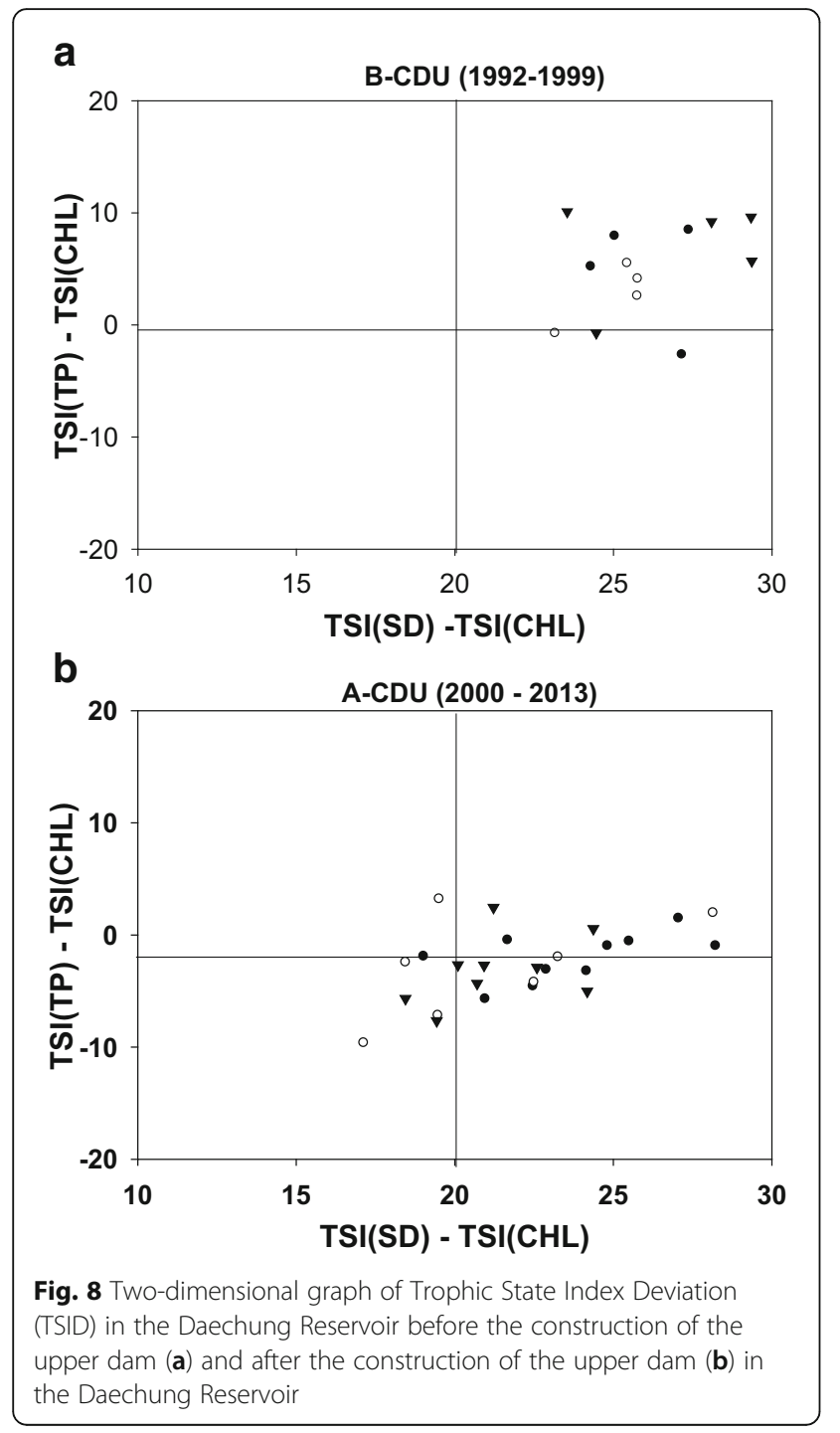

became more severe after the upper dam construction and effects of inorganic turbidity in the empirical relations were reduced. Thus, though heavy rainfalls during the monsoon occurred after year 2000, it did not result in light limitation or high inorganic turbidity. Thus, the response of CHL to the phosphorus increased after the upper dam construction. Also, slight increases in $\mathrm{pH}$, water temperature, and conductivity (as an indicator of ionic content) were observed in the reservoir. Overall, our analysis suggests that the upper dam construction modified the response of trophic components (phytoplankton) to the nutrients or nutrient ratios, which is closely associated with flow regime, resulting in modifications of ecological functions and trophic relations in the low trophic levels. Careful reservoir management or flow regime regulation of the upper dam (YD) is required in the future to reduce the eutrophication and algal blooms in DR.

\section{Abbreviations}

DR: Daechung Reservoir; TSIDs: Trophic State Index Deviations; MSL: Mean sea level; YD: Yongdam Dam; SDCs: Serial discontinuity concepts; TN: Total nitrogen; TP: Total phosphorus; TSS: Total suspended solids; CHL: Chlorophyll-a;

TSI: Trophic State Index; CUD: Construction of the upper dam

\section{Acknowledgements}

This research was supported by the fund of "2015' CNU Research Project," Chungnam National University.

\section{Authors' contributions}

KG got a project for the topic, and NPI analyzed the data with KG. NPI and KG wrote the manuscript and then edited together. All authors read and approved the final manuscript.

\section{Competing interests}

The authors declare that they have no competing interests.

Received: 22 December 2015 Accepted: 24 June 2016

Published online: 24 October 2016

\section{References}

An, K. G., \& Jones, J. R. (2000). Factors regulating bluegreen dominance in a reservoir directly influenced by the Asian monsoon. Hydrobiologia, 432, 3748.

An, K. G., \& Park, S. S. (2002). Indirect influence of summer monsoon on Chlorophyll-total phosphorous models in reservoirs: a case study. Ecological Modelling, 152, 192-203.

Canfield, D. J., \& Bachmann, R. W. (1981). Prediction of total phosphorus concentration, chlorophyll-a and Secchi depths in natural and artificial lakes. Canadian Journal of Fisheries and Aquatic Sciences, 38, 414-423.

Carlson, R. E. (1977). A trophic state index for lake. Limnology and Oceanography, 22, 361-369.

Cole, T. M., Hannan, H. H., et al. (1990). Dissolved oxygen dynamics. Chapter 4. In K. W. Thornton (Ed.), Reservoir Limnology: ecological perspectives. New York: Wiley.

Correll, D. L. (1999). Phosphorus: A rate limiting nutrient in surface waters. Poultry Science, 78, 674-682.

Havens, K. E., James, R. T., East, T. L., \& Smith, V. H. (2003). N:P ratios, light limitation and cyanobacterial dominance in a subtropical lake impacted by non-point source nutrient pollution. Environmental Pollution, 122, 379-390.

Irigoien, X., \& Castel, J. (1997). Light Limitation and Distribution of Chlorophyll Pigments in a Highly Turbid Estuary: the Gironde (SW France). Estuarine, Coastal and Shelf Science, 44, 507-517.

Kennedy, R. H., Thornton, K. W., \& Gunkel, R. C. (1982). The establishment of water quality gradients in reservoirs. Canadian Water Resources Journal, 7, 71-87.

Kennedy, R. H., Thornton, K. W., \& Ford, D. (1985). Characterization of the reservoir ecosystem. In D. Gunnison (Ed.), Microbial processes in reservoirs. Boston: Dr. W. Junk Publishers.

Kimmel, B.L. and A.W. Groeger. 1984. Factors controlling primary production in lakes and reservoirs; A perspective. In: Lake and Reservoir Management. U.S. EPA-440/5-84-001. Pp. 277-281.

Kimmel, B. L., Lind, O. T., \& Paulson, L. H. (1990). Reservoir primary production. Chapter 6. In K. W. Thornton et al. (Eds.), Reservoir Limnology: Ecological Perspectives. New York: Wiley.

Lehman, P. W., Sommer, T., \& Rivard, L. (2007). The influence of floodplain habitat on quantity and quality of riverine phytoplankton carbon produced during the flood season in San Francisco Estuary. Aquatic Ecology, 42, 363-378.

Moss, B. R. (1998). lonic contents in the lake water were diluted by the rainwater and most pronounced in the riverine zone by high flow. Ecology of Fresh Waters: Man and Medium, Past to Future. By, school of biological sciences, university of Liverpool. UK: Blackwell Publishing.

Oberholster, P. J., Dabrowski, J., \& Botha, A. M. (2013). Using modified multiple phosphorus sensitivity indices for mitigation and management of phosphorus loads on a catchment level. Fundamental and Applied Limnology/ Archiv für Hydrobiologie, 182, 1-16.

O'Boyle, S., Wilkes, R., McDermott, G., Longphuirt, S. N., \& Murray, C. (2015). Factors affecting the accumulation of phytoplankton biomass in Irish estuaries and nearshore coastal waters: A conceptual model. Estuarine, Coastal and Shelf Science, 155, 75-88. 
Oh, H. M., Lee, S. J., Kim, J. H., Kim, H. S., \& Yoon, B. D. (2001). Seasonal Variation and Indirect Monitoring of Microcystin Concentrations in Daechung Reservoir, Korea. Applied Environmental Microbiology, 67, 1484-1489.

Park, J. H., Duan, L., Kim, B., Mitchell, M. J., \& Shibata, H. (2010). Potential effects of climate change and variability on watershed biogeochemical processes and water quality in Northeast Asia. Japan Environment International, 36, 212-225.

Prepas, E. E., \& Rigler, F. A. (1982). Improvements in qualifying the phosphorus concentration in lake water. Canadian Journal of Fisheries and Aquatic Sciences, 39, 822-829.

Puckridge, J. T., Walker, K. R., \& Costelloe, J. F. (2000). Hydrological persistence and the ecology of dryland rivers. Regulated Rivers: Research \& Management, 16, 385-402.

Sartory, D. P., \& Grobbelaar, J. U. (1984). Extraction of chlorophyll-a from freshwater phytoplankton for spectrophotometric analysis. Hydrobiologia, 114, 177-187.

Sedell, J. R., Reeves, G. H., Hauer, F. R., Stanford, J. A., \& Hawkins, C. P. (1990). Role of refugia in recovery from disturbances: Modern fragmented and disconnected river systems. Section 4. Ecosystem and Landscape Constraints on Lotic Community Recovery Environmental Management, 14, 711-724.

Sterner, R. W. (2008). On the Phosphorus Limitation Paradigm for Lakes. International Review of Hydrobiology, 93, 433-445.

Straskraba, M. (1996). Lake and reservoir management. Verhandlungen des Internationalen Verein Limnologie, 26, 193-209.

Ward, J.V. and J.A. Stanford (1983). The serial discontinuity concept of lotic ecosystem. . In (eds, T.D. Fontaine and S.M. Bartel), Dynamics of lotic ecosystems (pp 29-42). Ann Arbor, Michigan, USA.

Wetzel RG (2001). Limnology: lake and river ecosystems 3rd Edition, ISBN: 978-0-12744760-5.

\section{Submit your next manuscript to BioMed Central and we will help you at every step:}

- We accept pre-submission inquiries

- Our selector tool helps you to find the most relevant journal

- We provide round the clock customer support

- Convenient online submission

- Thorough peer review

- Inclusion in PubMed and all major indexing services

- Maximum visibility for your research

Submit your manuscript at www.biomedcentral.com/submit 